\title{
PSA density: The comeback kid?
}

\section{Chris Morash, MD, FRCSC}

Medical Director, The Ottawa Hospital Prostate Cancer Assessment Centre, Ottawa, ON
See related article on page 46 .

Cite as: Can Urol Assoc J 2012;6(1):51-2. http://dx.doi.org/10.5489/cuaj.12025

A fter the advent of prostate-specific antigen (PSA) use in prostate cancer detection over 20 years ago, we looked to PSA density (PSAD) to more accurately diagnose cancers by improving the specificity of PSA. PSAD has always struck us as a logical marker and collectively we wanted it to live up to its early promise. To use it clinically, however, we needed to subject our patients to transurethral ultrasound (TRUS) or TRUS biopsy to get some measure of prostate volume. In addition, enough studies failed to clearly show that PSAD could reliably and accurately help us separate cancers from benign disease; PSAD was therefore mostly relegated to the scrapheap of prostate markers and PSA derivatives. More recently, in light of new findings, we are rediscovering PSAD. Several recent papers have demonstrated that PSAD is helpful in predicting Gleason score (GS) upgrading at radical prostatectomy (RP) ${ }^{1,2}$ and GS upgrading on serial biopsies in men on active surveillance (AS) for apparent low-risk disease. ${ }^{3}$ Having a low PSAD score has also been shown to be a favourable prognostic variable in men who are candidates for AS. ${ }^{4}$ In light of this renewed enthusiasm, PSAD is increasingly being evaluated in surgical and AS series.

Sfoungaristos and Perimenis retrospectively looked at 285 eligible RP cases performed at their institution over a 10-year period. ${ }^{5}$ In cases where the pathologist provided the dimensions of the resected gland, the authors determined prostate volume and use the preoperative PSA to calculate PSAD. They found that PSAD was the most important predictor for adverse pathology, including positive margins, extracapsular disease, seminal vesicle invasion and lymph node involvement. Since they did not have preoperative TRUS volumes, they quoted a prior study which showed a strong correlation between TRUS volume and pathological volume. Therefore, they conclude that their study may be used to guide clinical practice when preoperative volumes are actually known. The authors also stated that this lack of TRUS volumes is a limitation of their study. This is certainly true and therefore the findings have limited clinical usefulness. Nonetheless, there are some interesting points for illustration here. This contemporary surgical series shows that PSAD discriminates between low-grade, organ-confined disease and locally advanced, higher grade tumours. This finding may have more relevance in potential AS patients.

A recent paper by Corcoran and colleagues demonstrated that PSAD is a very useful predictor of GS upgrading at RP in men with Gleason 6 and $3+4=7$ cancers. ${ }^{6}$ It is in this specific group of mostly low-risk patients where PSAD works best. We clearly need better markers to select men for AS and to predict for worse pathology than what is evident on the initial diagnostic biopsy. To look for unrecognized higher grade disease in our AS patients, we currently perform serial repeat biopsies in the first few years of surveillance. We are coming to understand that some of these occult tumours are located anteriorly and are not accounted for in the biopsy pathology. This also may explain much of the upstaging and upgrading in the accompanying article. ${ }^{5}$

So, why does PSAD perform better in these surgical and AS series? Part of the answer may lie in the populations being studied. In this month's article, there is a significant proportion of low Gleason score patients (55\% of the series). ${ }^{5}$ This is obviously true also for AS series. In these populations, the higher PSAD may be caused by the occult tumour volume and grade. It may lose its discriminatory power in the bulkier and initially high-grade tumours, as shown by Corcoran and colleagues. ${ }^{6}$ So, whereas PSAD has not been helpful in screening and detection, it may have found a new life in today's AS world of seeking out the unrecognized high-grade tumour. Further study of PSAD's role in predicting adverse or favourable outcomes in low-risk patients is warranted. 
Morash

Competing interests: None declared.

This paper has been peer-reviewed.

\section{References}

1. Magheli A, Hinz S, Hege C, et al. Prostate specific antigen density to predict prostate cancer upgrading in a contemporary radical prostatectomy series: a single center experience. J Urol 2010;183:126-31. http://dx.doi.org/10.1016/i.juro.2009.08.139

2. Tseng $\mathrm{KS}$, Landis $\mathrm{P}$, Epstein II, et al. Risk stratification of men choosing surveillance for low risk prostate cancer. J Urol 2010;183:1779-85. http://dx.doi.org/10.1016/i.juro.2010.01.001

3. Bul M, van den Bergh RC, Rannikko A, et al. Predictors of unfavorable repeat biopsy results in men participating in a prospective active surveillance program. Eur Urol 2012; 61:370-7. http://dx.doi. org/10.1016/j.eururo.2011.06.027
4. Kotb AF, Tanguay S, Luz MA, et al. Relationship between initial PSA density with future PSA kinetics and repeat biopsies in men with prostate cancer on active surveillance. Prostate Cancer and Prostatic Dis 2011;14:53-7. http://dx.doi.org/10.1038/pcan.2010.36

5. Sfoungaristos S, Perimenis P. PSA density is superior than PSA and Gleason score for adverse pathologic features prediction in patients with clinically localized prostate cancer. Can Urol Assoc J 2012;6:46-50. http://dx.doi.org/10.5489/cuaj.11079

6. Corcoran NM, Casey RG, Hong MK, et al. The ability of prostate-specific antigen (PSA) density to predict an upgrade in Gleason score between initial prostate biopsy and prostatectomy diminishes with increasing tumour grade due to reduced PSA secretion per unit fumour volume. BJU Int 2011; Nov 15. http:// dx.doi.org/10.1111/i.1464-410X.2011.10681.x [Epub ahead of print]

Correspondence: Dr. Christopher Morash, University of Ottawa, Department of Surgery, Division of Urology, The Ottawa Hospital-Civic Campus, 1053 Carling Avenue, Ottawa, ON KIY 4E9; fax: 613-761-5305; cmorash@ottawahospital.on.ca 